\title{
Efficacy of PD-1 \& PD-L1 inhibitors in older adults: a meta-analysis
}

\author{
Rawad Elias ${ }^{1}$, Anita Giobbie-Hurder ${ }^{2}$, Nadine Jackson McCleary ${ }^{3}$, Patrick Ott ${ }^{3}$, F. Stephen Hodi ${ }^{3}$ \\ and Osama Rahma ${ }^{3 *}$
}

\begin{abstract}
Background: Immune checkpoint inhibitors targeting PD-1/PD-L1 pathway demonstrated promising activities in variety of malignancies, however little is known regarding their efficacy in adults aged $\geq 65$ years.

Methods: We conducted a systematic review and a study-level meta-analysis to explore efficacy of ICls based on age, younger vs older than 65 years. We included in this analysis randomized controlled phase II or III studies in patients with metastatic solid tumors that compared efficacy of PD-1 or PD-L1 inhibitors to a non-PD-1/PD-L1 inhibitor. Aggregated estimates of overall survival (OS) and progression-free survival (PFS) are based on random/ mixed effects (RE) models to allow for heterogeneity between the studies.

Results: Initial search identified 53 articles, 17 were randomized controlled trials that compared nivolumab, pembrolizumab or atezolizumab to chemotherapy or targeted therapy. Only 9 trials reported hazard ratiios (HR) for OS based on age and were included in this meta-analysis. Out of those studies seven reported HR for PFS but only 4 studies included subgroup-analysis based on age for PFS. The overall estimated random-effects HR for death was 0.64 with $95 \% \mathrm{Cl}$ of $0.54-0.76$ in patients $\geq 65$ years vs. 0.68 with $95 \% \mathrm{Cl}$ of $0.61-0.75$ in patients $<65$ years. The overall estimated random-effects for HR for progression was 0.74 with $95 \% \mathrm{Cl}$ of $0.60-0.92$ in patients $\geq 65$ years vs. 0.73 with $95 \% \mathrm{Cl}$ of $0.61-0.88$ in patients $<65$ years.
\end{abstract}

Conclusions: PD-1 (nivolumab and pembrolizumab) and PD-L1 (atezolizumab) inhibitors had comparable efficacy in adults younger vs $\geq 65$ years.

\section{Background}

The advent of Immune Checkpoint Inhibitors (ICIs) changed the landscape of cancer treatment. Efficacy of PD-1 and PD-L1 antibodies has been established in a wide spectrum of solid and hematological malignancies. [1-10] However, although cancer is predominantly a disease of older adults, the clinical efficacy of ICIs in this population has not been specifically assessed. [11, 12] Published literature suggests that aging-associated immune changes may have an impact on the activity of checkpoint inhibitors, including PD-1 and PD-L1 inhibitors. [13] Cytotoxic CD8+ $\mathrm{T}$ cells in older adults were found to have decreased TCR (T cell receptor) diversity, reduced proliferative capacity, and increased sensitivity to apoptotic signals compared to younger adults [14-16]

\footnotetext{
* Correspondence: osamae_rahma@dfci.harvard.edu

${ }^{3}$ Department of Medical Oncology, Dana-Farber Cancer Institute, Harvard Medical School, Boston, MA, USA

Full list of author information is available at the end of the article
}

In some studies, aging was associated with decreased expression of CD28 on the surface of CD8+ T cells which leads to decreased immune activation. [17-19] Expression of CD57, a marker of senescence, was found to be increased on the surface of cytotoxic $\mathrm{T}$ cells of older adults contributing to a diminished anti-tumoral immunogenic response. [20, 21] In addition, the levels of perforin and granzyme, both essential for T cell's cytotoxic activity, were lower in older adults compared to younger individuals. [22] Interestingly, expression of PD1 was found to be increased on $\mathrm{T}$ cells of older adults and its blockade did not restore $\mathrm{T}$ cell activity to the same extent as in younger adults [22-24] Our understanding of the efficacy of PD-1 and PD-L1 antibodies in older adults is limited due to underrepresentation of this patient population in prospective clinical trials due to concerns about the safety profile of the investigated agents. [25] Consequently, we conducted a systematic 
review and a study-level meta-analysis to explore efficacy of ICIs based on age, younger vs older than 65 years.

\section{Methods}

\section{Search strategy and selection criteria}

We performed a Pubmed database search from January 2009 to December 2016 using the medical subject headings (MeSH) terms "pembrolizumab", "nivolumab", and "atezolizumab", the only Food and Drug Administration (FDA) PD-1/PD-L1 ICIs approved at the time this review was conducted. Search was done using the filter "clinical trial". The language was restricted to English. We then performed additional searches of Web of Science, ASCO meeting database, and ESMO meeting database using the same terms. We reviewed the "Drugs @FDA" database for randomized studies that did not report number of patients aged $\geq 65$ years enrolled on the trial or subgroup analysis for overall survival (OS) by age (younger vs $\geq 65$ years). Studies meeting all of the following criteria were included: (1) Randomized controlled phase II or III studies in patients with metastatic solid cancer (2) Studies comparing efficacy of PD-1 or PD-L1 inhibitors to a nonPD-1/PD-L1 inhibitor (3) Subgroup analysis for survival using a hazard ratio (HR) based on age performed in study or available in FDA label review. The selection process is shown in Fig. 1. Studies involving use of ICIs in hematologic malignancies were excluded from this meta-analysis.

\section{Data extraction}

Data extracted from eligible studies included: (1) Study characteristics (first author, year of publication, study name, design, phase, arms, National Clinical Trial (NCT) number (2) Study population (total number of randomized patients, total number in each arm, total number of patients younger than 65 years, total number of patients $\geq 65$ years, number of patients younger than 65 years in each arm, number of patients $\geq 65$ in each arm, median age, age range, mean age (3) HR for OS and for PFS (4) HR for OS and for PFS based on age subgroups (younger vs $\geq 65$ years). In the case of trials that did not include survival subgroup analysis by age, we reviewed each published trial's supplement and the FDA medical and statistical review available on the "Drugs @FDA" database.

\section{Statistical methods}

Aggregated estimates of OS and progression-free survival (PFS) are based on random/mixed effects (RE) models to allow for possible heterogeneity between the studies. Forest plots were used to summarize and visualize the HR with 95\% confidence intervals (CI) for each study and for the aggregated estimates from the RE models. For studies reporting separate HR estimates for $65-75$ and $>75$ years, a combined estimate ( $\geq 65$ years) was created using random effects modeling, and the combined estimate was used in the meta-analysis for that study. Chi-squared $p$-values from Cochran's $\mathrm{Q}$ statistic assessed study heterogeneity. Analyses were conducted using the "Metafor" package in $\mathrm{R}$ software (Version 3.2.3, The R Foundation for Statistical Computing). Statistical significance is defined as $P<0.05$; there were no corrections for multiple comparisons.

\section{Results}

\section{Search results and patient characteristics}

We identified 53 studies that matched our basic selection criteria of clinical trial involving one of the FDA-approved PD-1 and PD-L1 agents. Thirty-six non-randomized studies were excluded. Seventeen studies were reviewed, 8 out of those 17 studies were excluded as they did not contain OS subgroup analysis by age. Final analysis included 9 studies: (6 phase 3 studies, 2

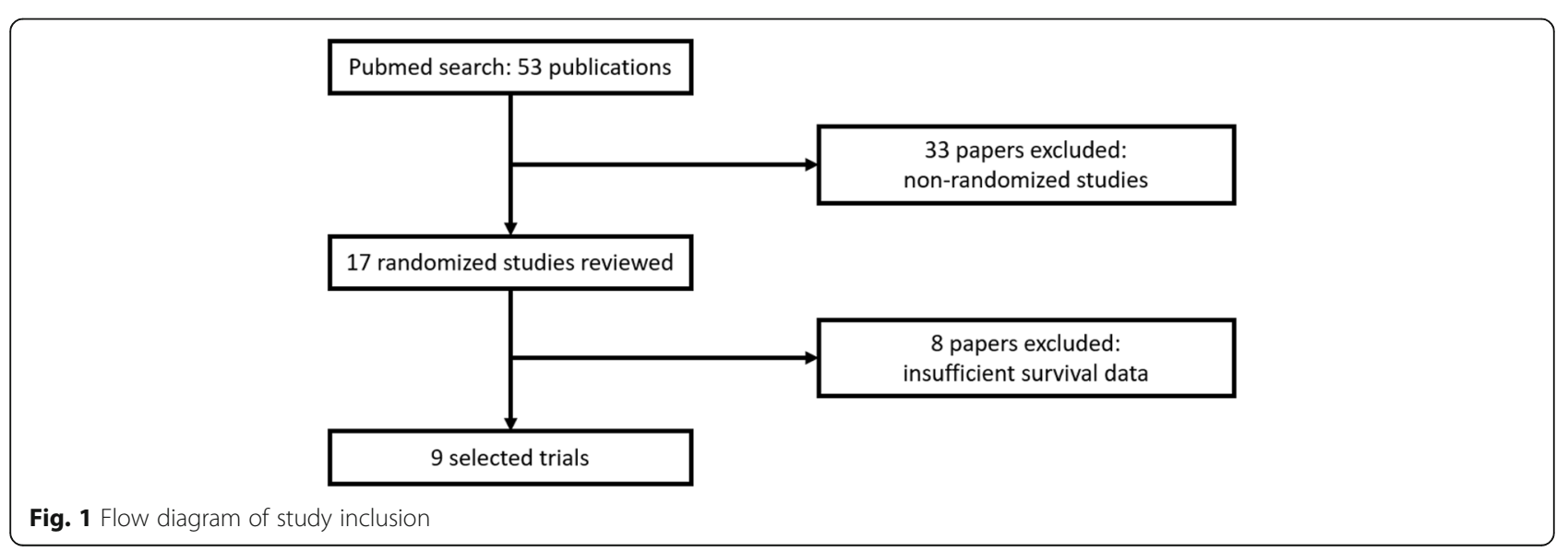




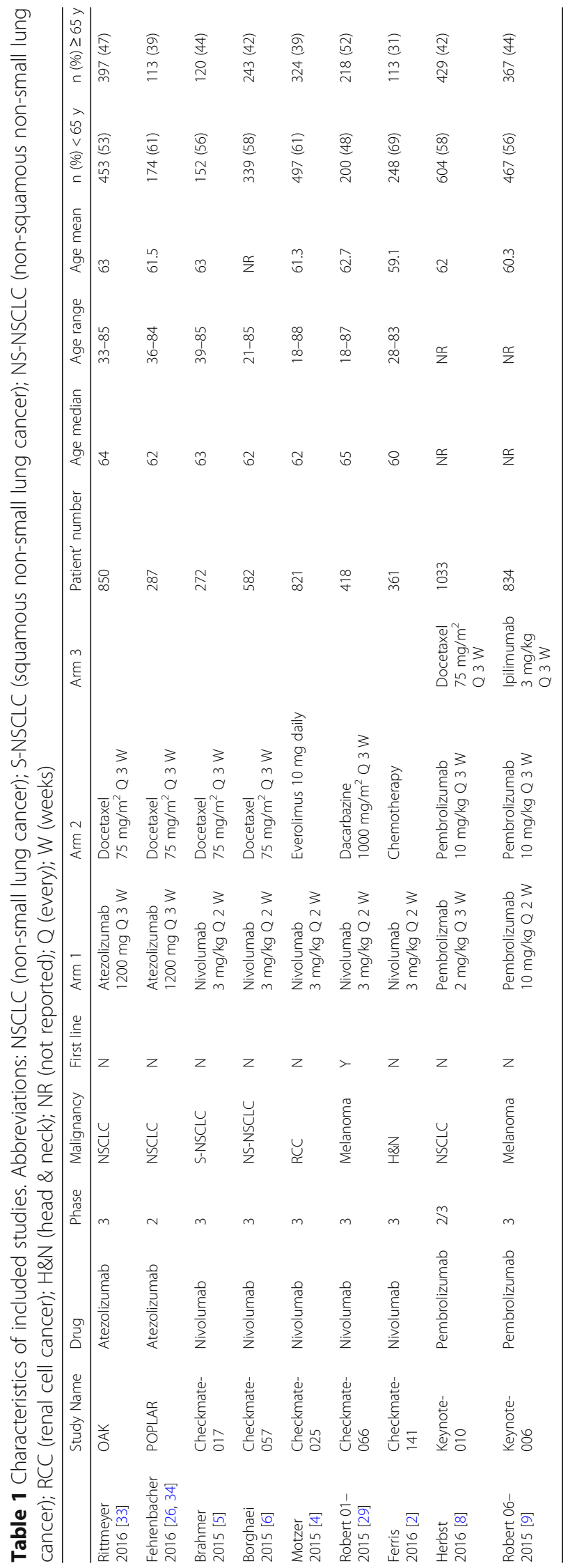


phase 2 studies, and one phase $2 / 3$ study). Among the 9 studies included in the analysis, 5 investigated nivolumab, 2 investigated pembrolizumab, and 2 investigated atezolizumab. Tumor types included metastatic nonsmall cell lung cancer (NSCLC) in 5 trials, melanoma in 2 , renal cell cancer in 1 , and head and neck cancer in one trial. Characteristics of each trial are presented in Table 1. All studies reported a subgroup analysis based on age except for the POPLAR study [26] for which HR were obtained from the FDA medical review of atezolizumab (Biologic License Application (BLA) 761,041).

\section{Overall survival}

\section{Overall comparison}

The endpoint of interest is overall survival in studies comparing PD1/PDL1 therapy with chemotherapy/targeted agents. The HR of the individual studies and the combined results based on the random-effects models are summarized in Fig. 2. The ratios presented compare anti-PD1/PDL1 agents against chemo/targeted therapy in the total population. The overall estimated, randomeffects HR is 0.69 with $95 \%$ CI of 0.63 to $0.74 \quad(P<0$. 0001). Based on the selected trials, there is evidence of a statistically significant, $31 \%$ reduction in the hazard of death with PD1/PDL1 therapy compared with chemo/ targeted agents. The chi-squared test for heterogeneity of studies was not significant $(P=0.52)$ suggesting that the reported results of the individual trials are not substantially different from one another.

\section{Survival according to age}

The studies selected for this meta-analysis included a total of 5458 patients. Age range of participants was 18-
89 years, and $2324(42.57 \%)$ patients were older than 65 years. The random-effects estimate of the HR of PD1/PDL1 agents compared to control therapy in patients under age 65 is 0.68 (95\% CI 0.61 to 0.75 ) (Fig. 3a). For this subset, there was no evidence of differences between the individual studies (chi-squared $P=0.45)$ in the analysis. The random-effects estimate of the HR for age 65 or older is 0.64 (95\% CI 0.54 to 0.76) (Fig. 3b). For this subset, there was evidence of differences in the HR between the individual studies (chi-squared $P=0.03$ ), suggesting considerable variability in the reported results among the studies. The comparable hazard ratios for patients 65 and older compared with those under $65(0.64$ vs. 0.68$)$ as well as the substantial overlap of the confidence intervals of the two estimates would indicate that the effects of therapy on survival did not vary for older or younger adults (Table 2).

\section{Progression-free survival \\ Overall progression-free survival}

The endpoint of interest is progression-free survival in studies comparing PD1/PDL1 therapy with chemotherapy/targeted agents. Among studies included in this analysis, seven had HR for overall PFS including four that reported HR for PFS according to age group. The HR for PFS of the individual studies and the combined results based on the random-effects models are summarized in Fig. 4. The overall estimated, random-effects HR is 0.74 with $95 \% \mathrm{CI}$ of 0.60 to $0.92(P=0.006)$. Based on the selected trials, there is evidence of a statistically significant, 26\% reduction in the hazard of a PFS event with PD1/PDL1 compared with chemo/targeted agents. The

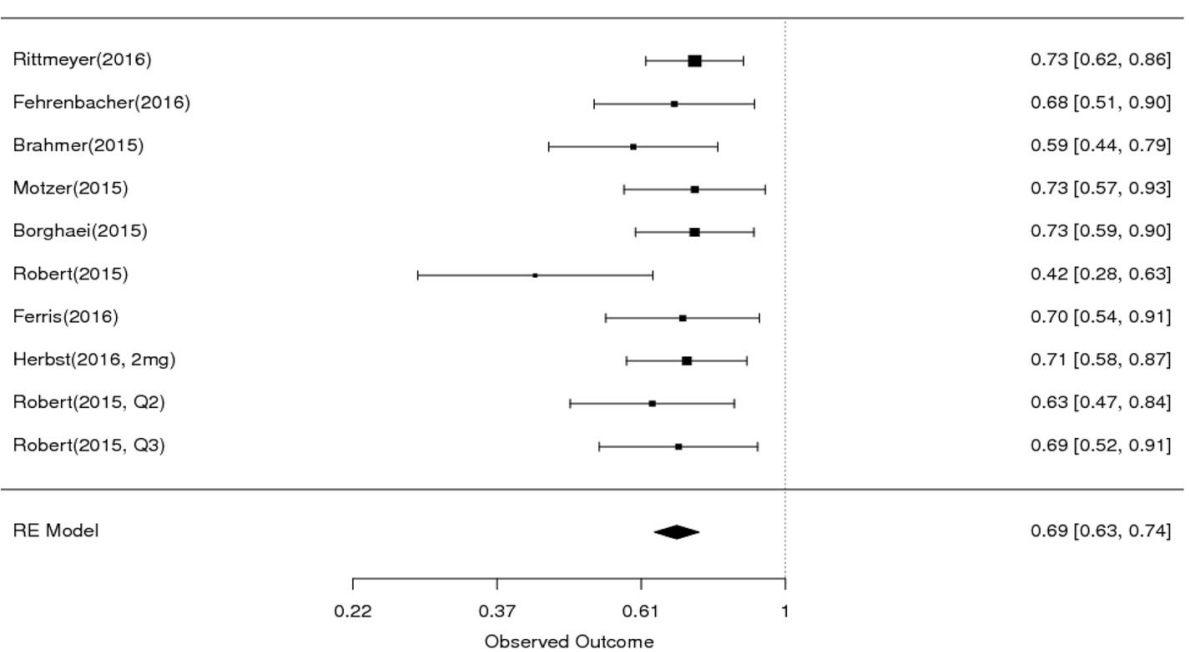

Fig. 2 Forest plot for OS. Studies are listed on the left and HR with $95 \% \mathrm{Cl}$ are on the right. Box sizes are inversely proportional to the standard error of the study; therefore, larger boxes indicate greater weight of the trial in the meta-analysis estimation. The HR from the Robert 01-2015 ${ }^{31}$ trial is lower than the others, but the weight of the trial is small and does not have great influence 
a

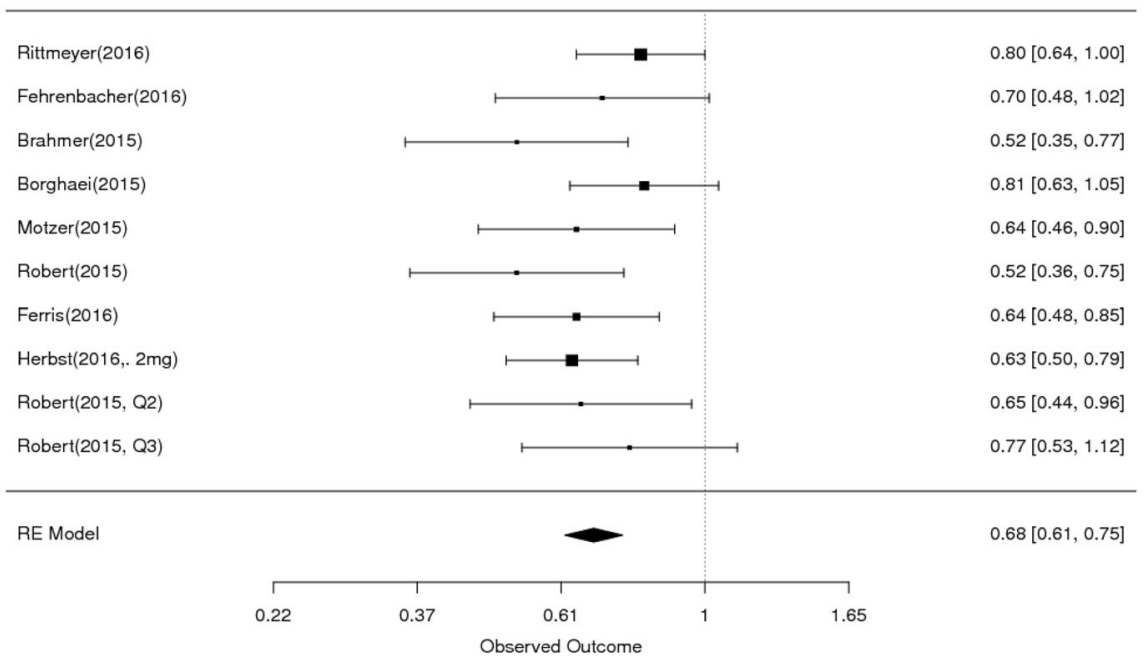

b

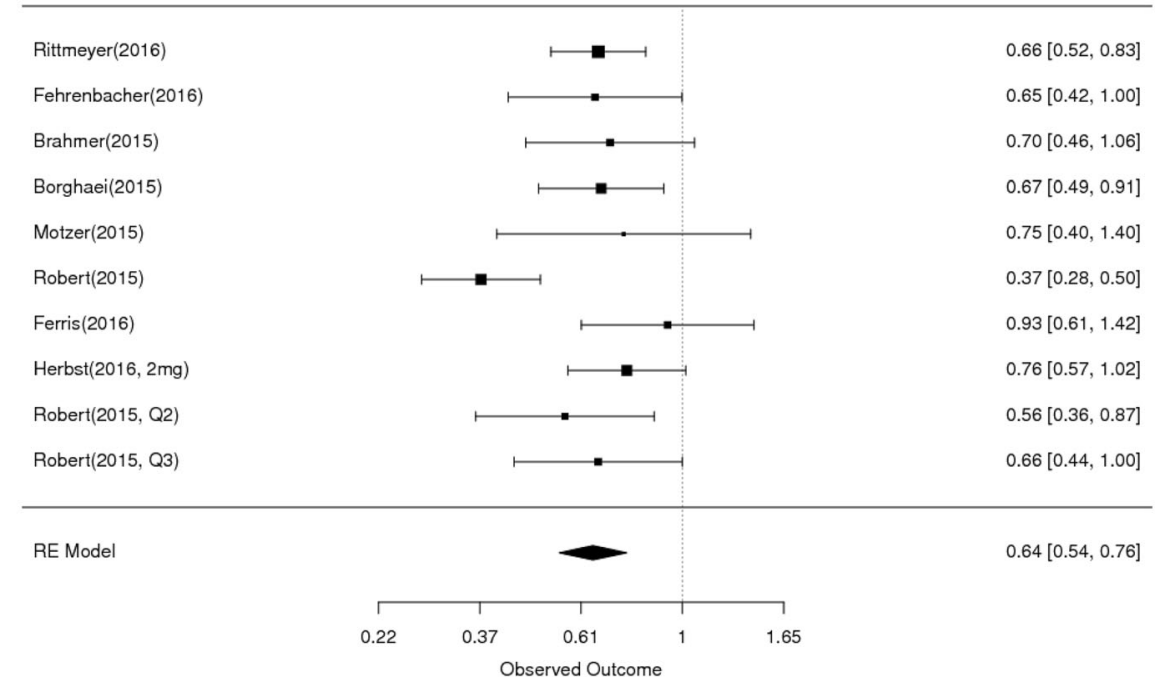

Fig. 3 Forest plot for OS for patients less than 65 years (A) and $\geq 65$ years (B). Studies are listed on the left and $H R$ with $95 \% \mathrm{Cl}$ are on the right. Box sizes are inversely proportional to the standard error of the study; therefore, larger boxes indicate greater weight of the trial in the meta-analysis estimation

chi-squared test for heterogeneity of studies was highly significant $(P<0.0001)$ suggesting that the reported HRs of the individual trials are substantially different.

\section{Progression-free survival according to age}

The random-effects estimate of the HR of PD1/PDL1 compared with chemo/targeted therapy in patients under age 65 is 0.73 (95\% CI 0.61 to 0.88 ) (Fig. 5a), and

Table 2 Summary of HR for OS by Age

\begin{tabular}{ll}
\hline Age & HR $(95 \% \mathrm{Cl})$ \\
\hline Age $<65$ years & $0.68(0.61$ to 0.75$)$ \\
Age $\geq 65$ years & $0.64(0.54$ to 0.76$)$ \\
\hline
\end{tabular}

for patients age 65 or over the HR estimate is 0.74 ( $95 \%$ CI 0.60 to 0.92 ) (Fig. 5b) For each subset of younger and older patients, there was evidence of heterogeneity between the studies (chi-squared $P=0.03$ and $p=0.05$, respectively), suggesting $t$ there is considerable variability in the reported results among the studies within each subset. The equivalent HR estimates for the two age cohorts along with the substantial overlap of the confidence intervals of the two estimates, would indicate that the effects of therapy upon PFS did not vary for older or younger adults (Table 3 ).

\section{Discussion}

Increased age is associated with changes in the host immunity that could impact effectiveness of ICIs therefore 


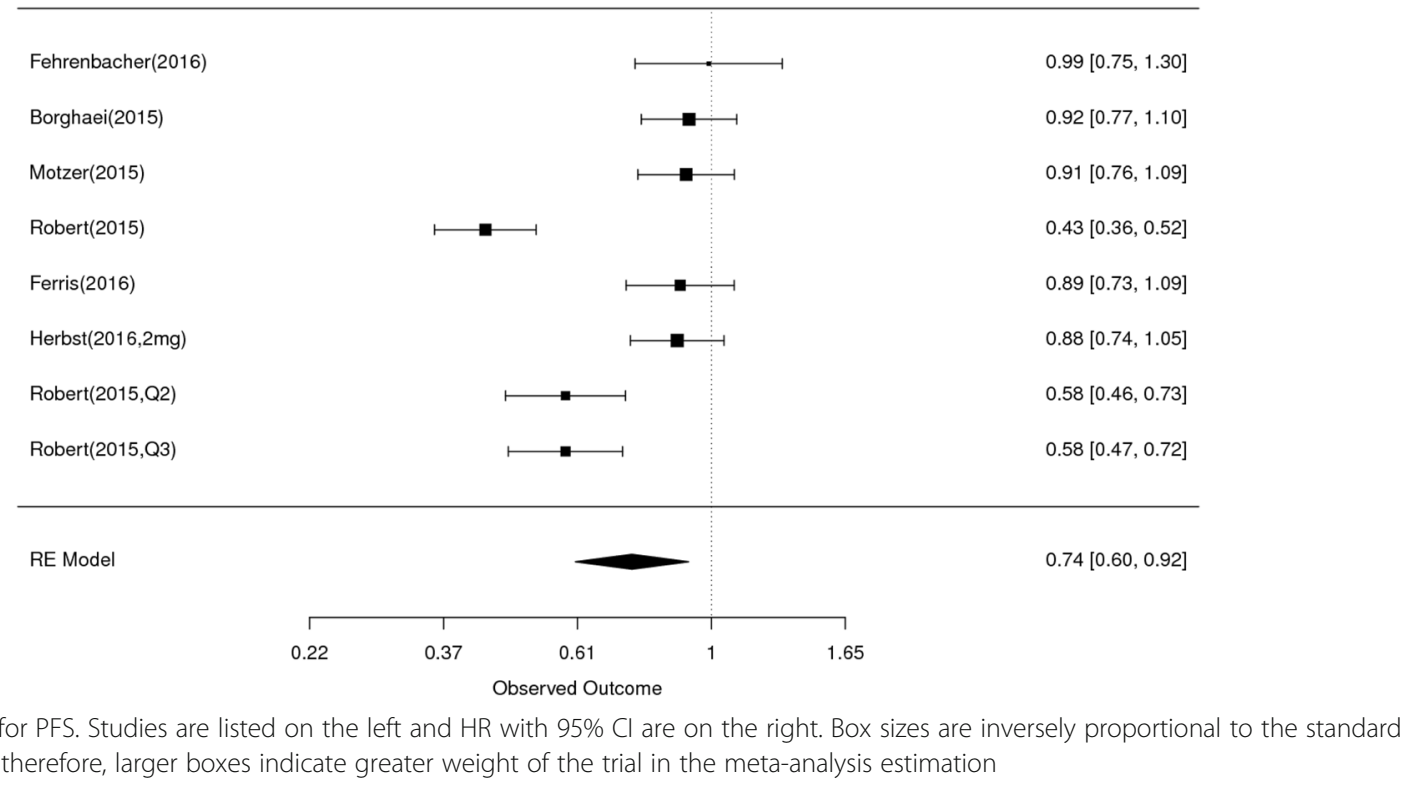

we aimed through this meta-analysis to evaluate the efficacy of PD-1 and PD-L1 inhibitors in adults $\geq 65$ years with advanced solid tumors compared to those < 65 years. This meta-analysis suggests that the impact of PD-1/PD-L1 inhibitors is comparable between adults younger vs. older than 65 years for OS [HR 0.68 (CI $0.61-0.75)$ vs. 0.64 (CI $0.54-0.76)$ ] and PFS [HR 0.73 (CI 0.61-0.88) vs. 0.74 (CI 0.60-0.92)]. The data were not sufficient to draw any conclusions specific to patients $\geq 75$ years. The number of patients older than 65 years enrolled in PD-1/PD-L1 studies is increased compared to what is usually seen in oncology trials but older adults remain under-represented in cancer clinical trials. $[25,27,28]$ This is particularly true for individuals older than 75 years who constitute more than $25 \%$ of newly diagnosed cases of cancer every year. [11] Four of the trials included in this review contained HR OS for patients $\geq 75$ years. $[4-6,29]$ However, out of 2093 individuals included in the analyzed trials only $10 \%$ (213) were $\geq 75$ year. Accordingly, data was not sufficient to draw any conclusions specific to adults $\geq 75$ years.

Few papers attempted to review this topic but only one was performed at a meta-analysis level. [30] The analysis performed by Nishijima et al..... was based on 9 studies, however among the trials included 4 were with an anti-CTLA4 agents, therefore mixing two classes of ICIs with different mode of action and efficacy profile. Authors showed a comparable OS benefit for ICIs in younger (HR $0.75,95 \%$ CI 0.68 to 0.82 ) and older adults (HR 0.73, 95\% CI 0.62-0.78). It is important to note the age cutoff was non-uniform across selected studies (65-70 years). In addition, authors did not show a statistically significant benefit in terms of PFS for ICIs in adults $\geq 65$ years (HR 0.77, $95 \%$ CI $0.58-1.01$ ) vs. a significantly favorable HR in patients $<65$ years (HR 0.58, 95\% CI $0.40-0.84$ ). Betof et al showed no significant difference in survival benefit with PD1/PDL1 inhibitors according to age in a retrospective analysis of patients treated in two academic medical centers. [31] However, this analysis included only patients with metastatic melanoma and 92.5\% were treated with an anti-PD1 agent.

Although it was done at a study-level, our paper constitutes the best level of evidence showing comparable efficacy for checkpoint inhibitors targeting checkpoint inhibitors in adults $>65$ years compared to younger patients. Studies included in this metaanalysis, consistent with the majority of clinical trials in oncology, used a numerical age cutoff. An arbitrary age cutoff is not sufficient to characterize "older" adults as aging is a highly variable physiological process. Older individuals are not a homogenous population, therefore measuring variables like functional status and comorbidity is essential to determine the physiologic "age" of an older adult [32]. In addition, older individuals enrolled in clinical trials tend to be adults aged 70-75 years, with good performance status, and a low number of comorbid medical conditions which does not represent the reallife population of older adults with cancer who often have functional limitations and multiple illnesses. 


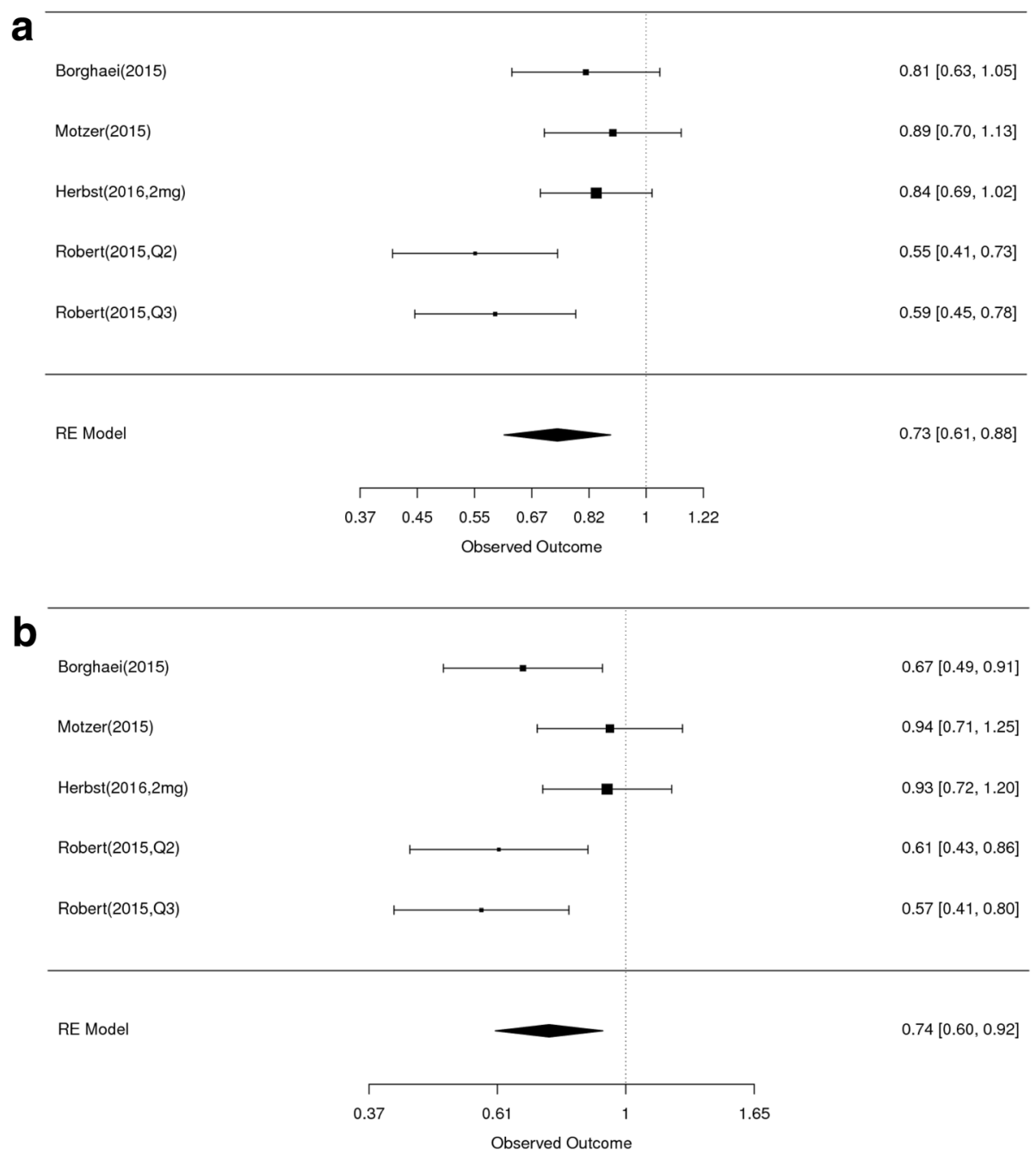

Fig. 5 Forest plot for PFS for patients less than 65 years (A) and $\geq 65$ years (B). Studies are listed on the left and HR with $95 \% \mathrm{Cl}$ are on the right. Box sizes are inversely proportional to the standard error of the study; therefore, larger boxes indicate greater weight of the trial in the meta-analysis estimation

Another limitation to our review is that data were obtained partially from FDA BLA review of a particular drug and not directly from the study itself as in the case of POPLAR study. [26]

In conclusion, our meta-analysis showed that improvement in survival associated with the use of PD-1/PD-L1 inhibitors is consistent across age cut-off of 65 years. More data are needed to understand efficacy among those aged $\geq 75$ years as well as

Table 3 Summary of HR for PFS by Age

\begin{tabular}{ll}
\hline Age & HR $(95 \% \mathrm{Cl})$ \\
\hline Age $<65$ years & $0.73(0.61$ to 0.88$)$ \\
Age $\geq 65$ years & $0.74(0.60$ to 0.92$)$ \\
\hline
\end{tabular}

tolerance and toxicity of ICIs in older adults overall. Further study is needed including comprehensive assessment of outcomes of significant to older adults, such as functional status and preservation throughout therapy. Geriatric assessment and biomarkers of aging and immune senesce will help to fully understand the impact of ICIs in this growing subset of adults diagnosed with cancer.

Acknowledgments

Not applicable

Funding

no funding to declare.

Availability of data and materials

All data generated or analyzed during this study are included in this published article. 


\section{Authors' contributions}

RE and OR conceived and designed research. Data collection and extraction was performed by RE and verified by OR. Statistical analysis was performed by AG-H. SH, PO, and NJMC participated in drafting article. All authors gave final approval to the version submitted.

\section{Ethics approval and consent to participate}

Not applicable

\section{Consent for publication}

Not applicable

\section{Competing interests}

The authors declare that they have no competing interests.

\section{Publisher's Note}

Springer Nature remains neutral with regard to jurisdictional claims in published maps and institutional affiliations.

\section{Author details}

${ }^{1}$ Sections of Hematology Oncology and geriatrics, Boston University School of Medicine, Boston, MA, USA. ${ }^{2}$ Department of Biostatistics \& Computational Biology, Dana-Farber Cancer Institute, Boston, MA, USA. ${ }^{3}$ Department of Medical Oncology, Dana-Farber Cancer Institute, Harvard Medical School, Boston, MA, USA.

Received: 15 January 2018 Accepted: 14 March 2018

Published online: 04 April 2018

\section{References}

1. Hodi FS, O'Day SJ, McDermott DF, Weber RW, Sosman JA, Haanen JB, Gonzalez R, Robert C, Schadendorf D, Hassel JC, et al. Improved survival with ipilimumab in patients with metastatic melanoma. N Engl J Med. 2010;363:711-23.

2. Ferris RL, Blumenschein G Jr, Fayette J, Guigay J, Colevas AD, Licitra L, Harrington K, Kasper S, Vokes EE, Even C, et al. Nivolumab for recurrent squamous-cell carcinoma of the head and neck. N Engl J Med. 2016:375:1856-67.

3. Weber JS, D'Angelo SP, Minor D, Hodi FS, Gutzmer R, Neyns B, Hoeller C, Khushalani NI, Miller WH Jr, Lao CD, et al. Nivolumab versus chemotherapy in patients with advanced melanoma who progressed after anti-CTLA-4 treatment (CheckMate 037): a randomised, controlled, open-label, phase 3 trial. Lancet Oncol. 2015:16:375-84.

4. Motzer RJ, Escudier B, McDermott DF, George S, Hammers HJ, Srinivas S, Tykodi SS, Sosman JA, Procopio G, Plimack ER, et al. Nivolumab versus Everolimus in advanced renal-cell carcinoma. N Engl J Med. 2015;373:1803-13.

5. Brahmer J, Reckamp KL, Baas P, Crino L, Eberhardt WE, Poddubskaya E, Antonia S, Pluzanski A, Vokes EE, Holgado E, et al. Nivolumab versus docetaxel in advanced squamous-cell non-small-cell lung Cancer. N Engl J Med. 2015;373:123-35.

6. Borghaei H, Paz-Ares L, Horn L, Spigel DR, Steins M, Ready NE, Chow LQ, Vokes EE, Felip E, Holgado E, et al. Nivolumab versus docetaxel in advanced nonsquamous non-small-cell lung Cancer. N Engl J Med. 2015:373:1627-39.

7. Reck M, Rodriguez-Abreu D, Robinson AG, Hui R, Csoszi T, Fulop A, Gottfried M, Peled N, Tafreshi A, Cuffe S, et al. Pembrolizumab versus chemotherapy for PDL1-positive non-small-cell lung Cancer. N Engl J Med. 2016;375:1823-33.

8. Herbst RS, Baas P, Kim DW, Felip E, Perez-Gracia JL, Han JY, Molina J, Kim JH, Arvis CD, Ahn MJ, et al. Pembrolizumab versus docetaxel for previously treated, PD-L1-positive, advanced non-small-cell lung cancer (KEYNOTE-010): a randomised controlled trial. Lancet. 2016:387:1540-50.

9. Robert C, Schachter J, Long GV, Arance A, Grob JJ, Mortier L, Daud A, Carlino MS, McNeil C, Lotem M, et al. Pembrolizumab versus Ipilimumab in Advanced Melanoma. N Engl J Med. 2015;372:2521-32.

10. Ribas A, Puzanov I, Dummer R, Schadendorf D, Hamid O, Robert C, Hodi FS, Schachter J, Pavlick AC, Lewis KD, et al. Pembrolizumab versus investigatorchoice chemotherapy for ipilimumab-refractory melanoma (KEYNOTE-002): a randomised, controlled, phase 2 trial. Lancet Oncol. 2015:16:908-18.

11. Browse the SEER Cancer Statistics Review 1975-2012 [https://seer.cancer. gov/archive/csr/1975_2012/browse_csr.php?sectionSEL=2\&pageSEL=sect_ 02_table.07.html].

12. Elias R, Morales J, Rehman Y, Khurshid H. Immune checkpoint inhibitors in older adults. Curr Oncol Rep. 2016;18:47.
13. Elias R, Karantanos T, Sira E, Hartshorn KL. Immunotherapy comes of age: immune aging \& checkpoint inhibitors. J Geriatr Oncol. 2017:8:229-35.

14. Gupta S, Gollapudi S. CD95-mediated apoptosis in naive, central and effector memory subsets of CD4+ and CD8+ T cells in aged humans. Exp Gerontol. 2008;43:266-74.

15. Koch S, Larbi A, Derhovanessian E, Ozcelik D, Naumova E, Pawelec G. Multiparameter flow cytometric analysis of CD4 and CD8 T cell subsets in young and old people. Immun Ageing. 2008;5:6.

16. Johnstone J, Millar J, Lelic A, Verschoor CP, Walter SD, Devereaux PJ, Bramson J, Loeb M. Immunosenescence in the nursing home elderly. BMC Geriatr. 2014:14:50

17. Czesnikiewicz-Guzik M, Lee WW, Cui D, Hiruma Y, Lamar DL, Yang ZZ, Ouslander JG, Weyand CM, Goronzy JJ. T cell subset-specific susceptibility to aging. Clin Immunol. 2008;127:107-18.

18. Weng NP, Akbar AN, Goronzy J. CD28(-) T cells: their role in the ageassociated decline of immune function. Trends Immunol. 2009;30:306-12.

19. Filaci G, Fravega M, Negrini S, Procopio F, Fenoglio D, Rizzi M, Brenci S, Contini P, Olive D, Ghio M, et al. Nonantigen specific CD8+ T suppressor lymphocytes originate from CD8+CD28- T cells and inhibit both T-cell proliferation and CTL function. Hum Immunol. 2004;65:142-56.

20. Brenchley JM, Karandikar NJ, Betts MR, Ambrozak DR, Hill BJ, Crotty LE, Casazza JP, Kuruppu J, Migueles SA, Connors M, et al. Expression of CD57 defines replicative senescence and antigen-induced apoptotic death of CD8+ T cells. Blood. 2003;101:2711-20.

21. Bigley AB, Spielmann G, LaVoy EC, Simpson RJ. Can exercise-related improvements in immunity influence cancer prevention and prognosis in the elderly? Maturitas. 2013;76:51-6.

22. Henson SM, Macaulay R, Riddell NE, Nunn CJ, Akbar AN. Blockade of PD-1 or p38 MAP kinase signaling enhances senescent human CD8(+) T-cell proliferation by distinct pathways. Eur J Immunol. 2015;45:1441-51.

23. Lages CS, Lewkowich I, Sproles A, Wills-Karp M, Chougnet C. Partial restoration of T-cell function in aged mice by in vitro blockade of the PD-1/ PD-L1 pathway. Aging Cell. 2010:9:785-98.

24. Vukmanovic-Stejic M, Sandhu D, Seidel JA, Patel N, Sobande TO, Agius E, Jackson SE, Fuentes-Duculan J, Suarez-Farinas M, Mabbott NA, et al. The characterization of varicella zoster virus-specific T cells in skin and blood during aging. J Invest Dermatol. 2015:135:1752-62.

25. Hurria A, Levit LA, Dale W, Mohile SG, Muss HB, Fehrenbacher L, Magnuson A, Lichtman SM, Bruinooge SS, Soto-Perez-de-Celis E, et al. Improving the evidence base for treating older adults with Cancer: American Society of Clinical Oncology statement. J Clin Oncol. 2015;33:3826-33.

26. Fehrenbacher L, Spira A, Ballinger M, Kowanetz M, Vansteenkiste J, Mazieres J, Park K, Smith D, Artal-Cortes A, Lewanski C, et al. Atezolizumab versus docetaxel for patients with previously treated non-small-cell lung cancer (POPLAR): a multicentre, open-label, phase 2 randomised controlled trial. Lancet. 2016;387:1837-46.

27. Talarico L, Chen G, Pazdur R. Enrollment of elderly patients in clinical trials for cancer drug registration: a 7-year experience by the US Food and Drug Administration. J Clin Oncol. 2004;22:4626-31.

28. Singh H, Kanapuru B, Smith C, Fashoyin-Aje LA, Myers A, Kim G, Pazdur R. FDA analysis of enrollment of older adults in clinical trials for cancer drug registration: a 10-year experience by the U.S. Food and Drug Administration. J Clin Oncol. 2017:35 abstr 10009

29. Robert C, Long GV, Brady B, Dutriaux C, Maio M, Mortier L, Hassel JC, Rutkowski P, McNeil C, Kalinka-Warzocha E, et al. Nivolumab in previously untreated melanoma without BRAF mutation. N Engl J Med. 2015;372:320-30

30. Nishijima TF, Muss HB, Shachar SS, Moschos SJ. Comparison of efficacy of immune checkpoint inhibitors (ICls) between younger and older patients: a systematic review and meta-analysis. Cancer Treat Rev. 2016:45:30-7.

31. Betof AS, Nipp RD, Giobbie-Hurder A, Johnpulle RAN, Rubin K, Rubinstein SM, Flaherty KT, Lawrence DP, Johnson DB, Sullivan RJ. Impact of age on outcomes with immunotherapy for patients with melanoma. Oncologist. 2017;22:963-71.

32. Extermann M, Hurria A. Comprehensive geriatric assessment for older patients with cancer. J Clin Oncol. 2007:25:1824-31.

33. Rittmeyer A, Barlesi F, Waterkamp D, Park K, Ciardiello F, von Pawel J, Gadgeel SM, Hida T, Kowalski DM, Dols MC, et al. Atezolizumab versus docetaxel in patients with previously treated non-small-cell lung cancer (OAK): a phase 3, open-label, multicentre randomised controlled trial. Lancet. 2016;389:255-65.

34. Atezolizumab BLA 761041 Medical Review [https://www.accessdata.fda.gov/ drugsatfda_docs/nda/2016/7610410rig1 s000MedR.pdf]. 